\title{
SubVersión DEl PARADIGMA NARCo EN EL RUIDO DE LAS COSAS AL CAER DE JuAN GABRIEL VÁSQUez*
}

\author{
Subversion of the Narco Paradigm in $E_{L}$ \\ RUIDO DE LAS COSAS AL CAER \\ by Juan Gabriel Vásquez
}

Adriana Sara Jastrzębska ${ }^{1}$

\footnotetext{
* Cómo citar este artículo: Jastrzębska, A S. (2021). Subversión del paradigma narco en El ruido de las cosas al caer de Juan Gabriel Vásquez. Estudios de Literatura Colombiana 49, pp. 213-230. DOI: https://doi. org/10.17533/udea.elc.n49a12

1 https://orcid.org/0000-0003-0794-1383 adriana.jastrzebska@uj.edu.pl Uniwersytet Jagielloński, Polska
}

Editores: Andrés Vergara Aguirre, Christian Benavides Martínez

Recibido: 15.02 .2021

Aprobado: 21.05.2021

Publicado: 30.06 .2021

Copyright: (C2021 Estudios de Literatura Colombiana. Este es un artículo de acceso abierto distribuido bajo los términos de la Licencia Creative Commons AtribuciónNo comercial - Compartir igual 4.0 Internacional
Resumen: El artículo propone una lectura de la novela $E l$ ruido de las cosas al caer (2011), de Juan Gabriel Vásquez, desde la perspectiva de la llamada convención y poética narco existente en la narrativa colombiana. El objetivo del trabajo es demostrar una paradójica condición de la obra analizada: manejando todos los ingredientes de dicha convención y poética narco, la novela retrata un fracaso de las ilusiones del narcotráfico como vía de ascenso social e individual, lo que la convierte en una suerte de antinarconovela y lleva a cierta subversión del paradigma narco.

Palabras clave: narconovela; Juan Gabriel Vásquez; novela colombiana; narconarrativas.

Abstract: This article proposes a reading of the novel $E l$ ruido de las cosas al caer (2011) by Juan Gabriel Vásquez from the perspective of the narco convention and poetics existing in Colombian narrative. The aim of the paper is to demonstrate a paradoxical condition of the novel: handling all the ingredients of the narco convention and poetics, the novel portrays a failure of the illusions of drug trafficking as a way of social and individual ascent, which makes it a kind of anti-narconovela and leads to a certain subversion of the narco paradigm.

Key words: narconovela; Juan Gabriel Vásquez; Colombian Fiction; narconarratives. 
La condición de la llamada narcoliteratura parece paradójica: pese a ser un fenómeno local o incluso localista, muy allegado a la realidad extratextual de América Latina, al mismo tiempo nace de una realidad globalizada y funciona debido al mercado editorial, también globalizado. Lo narco se ha convertido hoy en día en una marca comercial y un producto de consumo. El mercado dicta el planteamiento del tema del narcotráfico y determina la dimensión artística de sus representaciones. $\mathrm{Al}$ respecto, en su artículo bajo el elocuente título "De cómo leer el narcotráfico y otras advertencias”, Gabriela Polit Dueñas (2014) observa:

[...] lo que se consume como narcotráfico responde, entre otras cosas, a una serie de convenciones, de formas establecidas y de fórmulas que garantizan su comercialización. [...] lo que sobresale al hablar del narco es que en última instancia, se ha convertido en una suerte de marca, made in América Latina (p. 178).

Dueñas coincide en sus observaciones con Alejandro Herrero-Olaizola (2007), quien ve en la comercialización de la imagen violenta de la Hispanoamérica narco una promoción de “[...] cierta exotización de una realidad latinoamericana 'cruda' dirigida a un público más atento e instruido en cuestiones socio-políticas de América Latina y ansioso de leer algo nuevo, algo más light [...], pero con cierto 'peso cultural”' (p. 43). A lo largo de más de tres décadas de desarrollo, la narrativa del narcotráfico — de diversa calidad literaria - fue formando su convención particular y una suerte de canon literario, trascendiendo las fórmulas vigentes de la novela costumbrista, social, policíaca o psicológica. La investigación de la que deriva el presente artículo tiene por objetivo identificar y caracterizar los elementos que conforman lo que se puede llamar la convención y poética narco en la narrativa colombiana. El corpus analizado consta de 10 novelas publicadas entre 1993 y 2011 en las que el narcotráfico y sus secuelas han repercutido en la configuración estética y ética del mundo representado. Deliberadamente aplicamos a ellas la controvertida etiqueta de "narconovela", ${ }^{1}$ ya que interpretamos las obras en cuestión como un intento por parte de los escritores de captar los cambios culturales que conlleva el narcotráfico al trazar el trayecto de una sociedad y una cultura marcadas por el fenómeno, considerando la supuesta "complicidad" o "perspectiva criminalizadora” en términos puramente literarios y artísticos.

1 El concepto de "narconovela" o "narconarrativa" conlleva mucha controversia, debido a la fuerza del prefijo que, "a diferencia del adjetivo que determina un lugar concreto, $[. .$.$] anuncia una ruta que va más allá de lo que se$ pretende describir, es una señal o guiño que se hace para trazar un trayecto” (Olvera, 2013, p. 12). Según Luis Molina Lora (2011, p. 289) el prefijo "narco" implica cierta perspectiva criminalizadora. Ambos investigadores coinciden en notar y exponer cierta carga comprometedora que supone el prefijo. 
Nos concentramos en obras que, por varias razones, se dieron a conocer fuera de Colombia y gozaron de cierta visibilidad y resonancia en el mundo. E1 heterogéneo corpus de narconovelas colombianas se compone, pues, de novelas de Fernando Vallejo, Jorge Franco, Arturo Álape, Laura Restrepo, Darío Jaramillo Agudelo, José Libardo Porras y Gustavo Álvarez Gardeazábal; escritores consagrados en el panorama de las letras colombianas del último medio siglo y reconocidos en el mundo.

El análisis del corpus ha permitido catalogar varios ingredientes claves de lo que hemos llamado la convención y poética narco. Resulta que, en esta modalidad narrativa, los mundos representados se configuran a partir de contrastes y dicotomías que dan cuenta de las tensiones en el seno de la sociedad que generaron el narcotráfico. Los protagonistas se ven a menudo hiperbolizados, mitificados o desmitificados; en esta distorsión antirrealista resuenan "ecos" del pensamiento mítico. La narconarrativa suele, igualmente, entroncar con otros textos literarios, con otros medios y con la cultura de masas en general, ostentando intertextualidades e intermedialidades de todo tipo. Recurre a la primera persona gramatical, con frecuencia con claros rasgos de discurso oral, dando cuenta de la participación directa de las voces narrativas en los fenómenos descritos. El manejo de una gran variedad de registros y estilos permite interpretar la narconovela como enfrentamiento dinámico de paradigmas culturales distintos.

En este contexto hemos indicado la novela El ruido de las cosas al caer (2011) de Juan Gabriel Vásquez como un simbólico cierre del corpus: una obra cuya intención es captar el fenómeno narco desde una perspectiva histórica.

El presente artículo busca demostrar la paradójica condición de esta novela que, manejando los ingredientes de la convención y poética narco, se configura como una antinarconovela: a diferencia de otras narconovelas del corpus que retratan y expresan la progresiva erosión de la cultura, la sensibilidad y la axiología de la sociedad sometida a las consecuencias del narcotráfico, El ruido de las cosas al caer retrata, en definitiva, un fracaso total de las ilusiones del narcotráfico como vía de ascenso social e individual.

El ruido de las cosas al caer es una historia protagonizada y narrada por Antonio Yammara, profesor universitario de Derecho, que busca la verdad sobre la enigmática figura de Ricardo Laverde, a quien conoció en un billar del centro de Bogotá. Laverde recién había cumplido una pena de veinte años de cárcel por ser piloto de un cartel. Ambos comparten varios partidos de billar en los que hablan poco, pero 
de alguna manera implícita simpatizan. Cuando Ricardo es asesinado en la calle, Antonio resulta herido en el mismo atentado. En un largo proceso de recuperación física y psíquica, emprende una suerte de investigación para conocer post mortem a compañero de juego. Su búsqueda lo lleva a la hija de este, Maya, quien igualmente intenta llenar los blancos de la imagen del padre difunto. Antonio visita a la mujer en su finca de La Dorada y conoce la historia del expiloto y de su esposa norteamericana fallecida en el accidente aéreo del vuelo 965 de American Airlines. La reconstrucción de la historia de Ricardo y su esposa Elaine (Elena) en los años sesenta y setenta, realizada a partir de las memorias de Maya, compartidas y comentadas con Antonio Yammara, se ve complementada por los recuerdos que los dos, en aquel entonces niños o adolescentes, han conservado de aquel tiempo. De esta manera, se recrea una época de la historia reciente de Colombia y las huellas que ha dejado en por lo menos dos generaciones de colombianos: los padres, cómplices o víctimas del narcotráfico, y los hijos crecidos en la sombra de Pablo Escobar y cierta axiología perversa representada por él.

El título de la novela, un verso endecasílabo (De Maeseneer, 2013, p. 212), desde el principio evoca y anuncia la caída que puede entenderse literal y metafóricamente. En esta obra las cosas que hacen un ruido al caer son en primer lugar los aviones, símbolos de la globalización y del negocio de las drogas desarrollado por vías aéreas. Los aviones evocan también la caída de la vida de Ricardo Laverde tras ser arrestado durante uno de estos viajes, y el fracaso de su familia representado por la muerte de Elaine Fritts en un Boeing 757 estrellado contra una montaña. En su trabajo, Aníbal González (2016) analiza este y otros símbolos presentes en la novela de manera mucho más detallada:

Evidente símbolo ascensional, el avión es también un símbolo de riesgo, cuya ilusión de libertad y poderío (como se ve en las poéticas líneas donde Ricardo le explica a Elena la euforia que siente al volar) se deshace con el más leve error humano (como se ve en el casete del accidente aéreo) (p. 47I).

A su vez, la caída de la Hacienda Nápoles, la finca de Pablo Escobar, abandonada después de la muerte del capo, simboliza el fracaso de la narcocultura y del narcotráfico como vía de ascenso económico y social. Según Margarita Jácome (2016), se trata también de "la caída de la flor y nata de la sociedad bogotana en el mundo del tráfico de drogas” (p. 46). Por último, cae igualmente la vida personal y familiar del narrador, Antonio Yammara. 


\section{Terapia en plano colectivo. Dimensión temporal y humana}

Las bipolaridades en la construcción del mundo representado en El ruido de las cosas al caer se observan en tres dimensiones cruciales: la temporal, la espacial y la del mundo de los personajes.

$\mathrm{El}$ argumento de la novela se desarrolla en varios planos temporales. Empieza en 2009 con la noticia sobre la muerte de uno de los hipopótamos prófugos de la Hacienda Nápoles. La movida mediática provocada por el acontecimiento sirve como introducción y desentonador del relato, remitiendo al narrador, Antonio Yammara, al pasado y haciéndole recordar su brevísima "amistad" con Ricardo Laverde entre 1995 y 1996, además de la visita en casa de Maya Fritts en 1999. La historia de Ricardo y Elaine, reconstruida por Yammara y Maya, se ubica en los años 60 y a principios de los 70 del siglo pasado. La bipolaridad temporal se apoyará entonces en la dicotomía pasado/presente correspondiente en este caso a las experiencias de los padres (Ricardo y Elaine) y las de los hijos (Maya y Antonio), y también en los inicios del narcotráfico y sus consecuencias. En este eje temporal, entre los dos polos, se mueven los personajes, igualmente configurados de manera dicotómica como representantes de dos generaciones: unos investigados, los otros investigadores, unos responsables/culpables, los otros víctimas.

Unidos por la experiencia de haber crecido en la época del narcoterrorismo y por una visita clandestina al zoológico de la Hacienda Nápoles, probablemente el mismo día, Maya y Antonio, cómplices y socios en su pesquisa sobre el pasado, representan dos posturas distintas y complementarias. Antonio personifica "la memoria colectiva de toda una generación, una metáfora del oficio del novelista y al mismo tiempo de la deuda de toda una sociedad que sufre la enfermedad del olvido" (Fernández Luna, 2013, p. 36), mientras Maya Fritts "encarna la deuda con el pasado, es en definitiva, una metáfora de la melancolía de la sociedad colombiana que no ha podido interpretar ni superar el sentimiento doloroso de culpabilidad" (p. 37). Al mismo tiempo, la hija que reconstruye y cuenta la historia de sus padres difuntos puede verse en tanto símbolo y encarnación del duelo. Así, el encuentro y el trabajo de los dos adquiere, sobre todo, un valor terapéutico.

El profundo hiato entre las generaciones de los padres y de los hijos no significa desconexión. Se pueden observar unas claras analogías entre los personajes de Laverde y Yammara: padres incapaces de mantener sus familias unidas. La afición al billar que comparten cumple un importante papel simbólico; con sus trayectorias, choques 
y carambolas el juego ilustra otra dicotomía crucial: la de causalidad y casualidad en la vida humana (González, 2016, p. 471). Por debajo de la bipolaridad temporal y humana, subyace cierta continuidad, una conexión interpretable en este caso como legado o herencia. Las analogías entre personajes, actitudes y acontecimientos aparentemente opuestos constituyen un fundamento en el que se forja el carácter colectivo de la historia narrada.

\section{Caída libre. Dimensión espacial}

La configuración del mundo representado a partir de bipolaridades y contrastes se hace aún más visible en la dimensión espacial de la novela. No cabe duda que Bogotá constituye el centro del mundo representado, y la principal bipolaridad de la configuración del espacio novelado es la de dentro/fuera de la capital colombiana. Luis Henao Uribe (2018) sostiene que El ruido de las cosas al caer

[...] reproduce una cartografía discursiva que históricamente ha ordenado a Colombia según una relación centro-provincias, letrado-otro. Al retomar los discursos liberales del siglo xix, El ruido presenta una distribución del espacio nacional, en la cual Bogotá se propone como centro intelectual y las provincias como espacios de las pasiones y violencias (p. I59).

Antonio Yammara es bogotano, de nacimiento y de convicción. Conoce a Ricardo Laverde en un local de billares en La Candelaria, el centro histórico de la ciudad. El posterior trauma a raíz del atentado le impide volver allí, le "roba" esta parte de la ciudad. Dice el protagonista:

Así perdí una parte de la ciudad; o, por mejor decirlo, una parte de mi ciudad me fue robada. Imaginé una ciudad en que las calles, las aceras, se van cerrando poco a poco para nosotros, como las habitaciones de la casa en el cuento de Cortázar, hasta acabar por expulsarnos. [...] Después de que la calle i4 me fuera robada [...] comencé a aborrecer la ciudad, a tenerle miedo, a sentirme amenazado por ella (Vásquez, 20II, p. 6\%).

Cuando por fin logra volver a la calle 14, su percepción del lugar está marcada por lo ocurrido. De esta manera, Bogotá se va convirtiendo en una suerte de archivo, que puede ser "leído" o "narrado" como una historia.

Para curar su trauma y resolver el enigma de Laverde, Yammara debe salir de la ciudad. La parte más importante de la pesquisa transcurre en la provincia, en la tierra caliente, que efectivamente se relaciona con "pasiones y violencias": el amor de $\mathrm{Ri}$ cardo y Elaine, y sus vínculos con el narcotráfico. Igualmente, para superar la trágica suerte de su familia, Maya Fritts se escapa de Bogotá. 
Mientras las bipolaridades y tensiones entre el centro y la provincia, asociados con la civilización y la barbarie, constituyen uno de los temas más tradicionales en la literatura latinoamericana y una seña de identidad de la configuración de sus discursos espaciales, Juan Gabriel Vásquez añade al espacio novelesco una dimensión nueva al construir un espacio vertical. Lo diseñan en primer lugar los aviones, objetos protagonistas de la novela, claros símbolos de la modernidad y globalización, que suben y caen, determinando el desarrollo de la trama y marcando puntos cruciales de la vida de los personajes y la historia del país. La dicotomía arriba/abajo, que se aprecia desde el propio título del libro, es fundamental en la interpretación de la novela. Además de proseguir el legado de su abuelo, piloto y héroe nacional, Laverde quiere pilotear los aviones porque ve en esta actividad una vía para su ascenso social y económico. Cada vuelo "coronado" de droga significa un progreso económico de su familia. La caída de Laverde empieza cuando es arrestado con una de estas cargas. Para evitar que la pequeña Maya se entere del encarcelamiento, Elaine le explica a la hija que su padre murió cayendo del cielo al mar. En esta visión, el último vuelo solitario puede interpretarse como metáfora de la vida de Ricardo, marcada por el éxito y la tragedia, por el ascenso y la caída, por un juego —el billar — de casualidades y causalidades:

Le explicó que Ricardo se había perdido en el cielo. A los pilotos les pasaba eso de vez en cuando [...]. El cielo era muy grande y el mar era muy grande también y un avión era una cosa muy pequeña y los aviones que manejaba papá eran los más pequeños de todos, y el mundo estaba lleno de aviones como ésos, aviones pequeños y blancos que despegaban y volaban un rato sobre la tierra y luego salían a volar sobre el mar, y llegaban a estar lejos, muy lejos, lejos de todo, completamente solos, sin nadie que les diga por dónde se llega otra vez a la tierra. $Y$ a veces pasaba algo, y se perdían. Se les olvidaba dónde quedaba adelante y dónde quedaban atrás, o se confundían y empezaban a volar en círculos sin saber dónde estaba atrás y dónde adelante, dónde la izquierda y dónde la derecha, hasta que el avión se quedaba sin gasolina y se caía al mar, se caía desde el cielo como una niña que se tira a una piscina. Y se hundía, sin ruido ni estrépito, se hundía sin ser visto porque en esos lugares no hay vida, y allí, en el fondo del mar, a los pilotos se les acababan los años (Vásquez, 2011, pp. 218-219).

Tal verticalidad de ascenso y caída, en plano metafórico, se observa en las experiencias vitales y las relaciones de otros personajes: Antonio y su familia, Elena Fritts o Mike Barbieri, voluntario de los Cuerpos de Paz convertido en mafioso.

Estos movimientos verticales resultan también de la propia geografía del mundo representado, de la ubicación de Bogotá a unos 2600 m.s.n.m., hecho al que volveremos en el análisis del siguiente ingrediente de la narconovela presente en El ruido de las cosas al caer: distorsión antirrealista de los actores del narcotráfico a través de su mitificación/desmitificación. 


\section{Descenso y resurrección}

En este caso específico los "actores" del narcotráfico no son solamente los personajes, aunque la primera figura de tinte mitificado es, desde luego, Ricardo Laverde, hombre-enigma. La historia reconstruida por Antonio y Maya se puede interpretar como una prueba de devolverle la vida al expiloto y, simbólicamente, darle la voz, al igual que en una especie de sesión espiritista, para que explique sus motivaciones más profundas. Acabamos de mencionar algunas analogías y conexiones entre Yammara y Laverde; en el caso de su dimensión espiritual, también resultan interconectados y, de cierta manera, unidos. María Victoria Albornoz Vásquez (2017) observa incluso que "la muerte de Laverde señala también la muerte simbólica del narrador"(p. 57), lo que nos parece acertado en el sentido de que, a partir de este momento, Antonio pierde su tranquilidad y empieza a cometer errores que acabarán por arruinar su vida personal.

El viaje de Antonio a La Dorada, para reconstruir y rescatar la figura borrosa de Ricardo, es interpretable en categorías escatológicas o religiosas como una muerte y resurrección simbólicas, un descenso del propio narrador al infierno para volver a la vida al tercer día. Es significativo que Yammara emprenda su viaje a la finca de Maya Fritts el Viernes Santo de 1999, suspendiendo su vida cotidiana y abandonando de improviso sus compromisos. El viaje es en realidad un descenso, de connotaciones “infernales" por el cambio de temperatura, ya que, desde la altura de Bogotá, el protagonista debe

[...] hacer un descenso drástico, y así pasar en cuestión de tres horas de nuestros dos mil seiscientos metros fríos y lluviosos al valle del río Magdalena, donde algunos lugares quedan por debajo del nivel del mar y las temperaturas pueden acercarse en ciertas zonas malhadadas a los cuarenta grados centígrados (Vásquez, 20II, p.91).

El descenso de Antonio se ve marcado por ciertos detalles que dotan al paisaje de borrosidad y, por lo tanto, de irrealidad:

En el Alto del Trigo una neblina dura bajó sobre los viajeros, repentina como una nube que hubiera perdido el rumbo, y la visibilidad casi nula me obligó a reducir tanto la marcha que las campesinas en bicicleta iban más rápido que yo. La neblina se acumulaba en el vidrio como rocío, de manera que era necesario usar los limpiaparabrisas aunque no hubiera lluvia, y las figuras - el carro de adelante, un par de soldados flanqueando la vía con sus metralletas terciadas, un burro de cargasurgián poco a poco entre aquella sopa lechosa que no dejaba pasar la luz. [...] Y luego, al bajar hacia Guaduas, la neblina se levantó como se había posado, y de repente se abrió el cielo y un golpe de calor transformó el día: estalló la vegetación, estallaron los olores, aparecieron puestos de frutas a la vera del camino (pp. 96-97, las cursivas son mías). 
Al llegar al valle del Magdalena, el narrador entra en el mundo rural de la tierra caliente que evoca la línea magicorrealista de la literatura colombiana: superabundancia de plantas, colores y olores, combinada con cierta atemporalidad, expresada en este caso en una mezcla de modernidad, abandono estatal y naturaleza. Su primer encuentro con Maya igualmente se tiñe de irrealidad, ya que, a la llegada del visitante, la mujer está inspeccionando las colmenas, con su traje de apicultora que la convierte en un "monstruo blanco" (p. 99). El viaje del protagonista va adquiriendo una dimensión transcendental, mítica: Yammara suspende su propia vida para encontrar en la tierra caliente a Maya, quien le ayudará a diagnosticar y superar un trauma colectivo de toda una generación de bogotanos.

\section{Hacienda Nápoles revisitada}

Antonio sale de Bogotá en busca de la historia de Ricardo y termina conociendo las raíces del narcotráfico, las cuales suelen ubicarse en la "otra" Colombia, la de la provincia que "supone un debilitamiento de la ley y de la moral que configuran los modos de ser en la capital” (Henao Uribe, 2018, p. 167). La culminación de la experiencia de autoreconocimiento y terapia generacional se da con la visita de Antonio y Maya a las ruinas de la Hacienda Nápoles al tercer día de su encuentro, lo cual refuerza la interpretación religiosa de la experiencia del protagonista, pues sucede durante un domingo que

[...] los cristianos llaman de Pascua y en el cual se celebra o se conmemora la resurrección de Jesús de Nazaret, que había sido crucificado dos días antes (más o menos a la misma hora en que yo comenzaba mi primera conversación con la hija de Ricardo Laverde) y que a partir de ahora comenzaría a aparecerse a los vivos (Vásquez, 2011, p. 214).

La más conocida de las fincas de Pablo Escobar en el imaginario colombiano y en El ruido de las cosas al caer aparece cual "monumento al poderío económico y a la excentricidad de la narcocultura. El espacio funciona a modo de sinécdoque de los lugares ocupados por la cultura narco que transformaron violentamente la geografía nacional" (Henao Uribe, 2018, p. 167). La Hacienda Nápoles, en ausencia de su antiguo propietario, se configura como un símbolo visible y palpable del narcotráfico y, en relación con los fenómenos de mitificación y desmitificación de que estamos hablando, cobra protagonismo indudable. Su valor simbólico es multidimensional: la hacienda simboliza a Pablo Escobar, el impacto del narcotráfico y la narcocultura en la realidad colom- 
biana, y la complicidad de los colombianos que, seducidos por el lugar —al punto de convertirlo en destino de excursiones domingueras de familias con niños que visitan el legendario zoológico-, se desentienden de la actividad criminal de su amo.

La alusión a la hacienda dota a la novela de un carácter circular: El ruido de las cosas al caer abre con la noticia sobre un hipopótamo prófugo y cazado, y finaliza con la visita en la finca, cierre simbólico del encuentro de Maya y Antonio. Semejante a un mito desmitificado, el lugar demuestra el fracaso del narcotráfico como una vía del éxito individual y/o colectivo.

El mito de la Hacienda Nápoles se fundamenta en los recuerdos infantiles de los protagonistas, mezclados con la imagen mediática amarillista. Antonio y Maya pertenecen a la generación de colombianos que solía visitar dicha hacienda como un lugar casi mágico donde los niños excitados podían ver

[...] al canguro que daba patadas a un balón de fútbol, $[\ldots .$.$] al famoso loro que era capaz de recitar$ la alineación de la selección Colombia, [...] a los emús, [...], a los leones y los elefantes que Escobar había comprado a un circo viajero, $[\ldots .$.$] a los caballos enanos [\ldots]$ a los rinocerontes, $[\ldots .$.$] al increíble$ delfín rosado (Vásquez, 20II, p. 234).

El hecho de que los dos hubieran ido allí a escondidas (y probablemente el mismo día) refuerza la imagen de la finca como un territorio maravilloso y, por prohibido, aun más atrayente. En los recuerdos que los protagonistas conservan de ese lugar, al igual que en narraciones magicorrealistas, se mezclan la realidad y la fantasía. Por su narcoextravagancia y estatus de fruta prohibida, de seducción y tabú, la hacienda se configura en tanto territorio de transgresión. La Hacienda Nápoles de los ochenta es una suerte de leyenda en boca de todos que se convirtió en una referencia importante en el imaginario colombiano o hasta en una especie de seña de identidad de toda una generación:

[Laverde] No dijo nada más: no dijo, por ejemplo, a qué animales se refería, ni cómo sabía que se estaban muriendo de hambre. Pero nadie se lo preguntó, porque todos allí teníamos edad suficiente para haber conocido los mejores años de la Hacienda Nápoles. El zoológico era un lugar de leyenda que, bajo el aspecto de la mera excentricidad de un narco millonario, prometía a los visitantes un espectáculo que no pertenecía a estas latitudes (Vásquez, 20II, p. 20).

Tras reconstruir la historia de Laverde y su esposa, Maya y Antonio deciden trasladar su investigación del pasado personal hacia lo social e histórico: visitar nuevamente la Hacienda Nápoles, usando el mismo carro que Ricardo había comprado en sus primeros años de trabajo para el cartel, lo que indica cierta continuidad entre el pasado 
y el presente, entre los orígenes del narcotráfico y sus consecuencias. A medida que se acercan a la finca, surgen cada vez más recuerdos y preguntas por el pasado; el viaje se convierte en un recorrido por la historia reciente de Colombia, vista desde una perspectiva íntima de dos adolescentes de la época:

\section{“¿Dónde estaba usted cuando mataron a Lara Bonilla?”}

La gente de mi generación hace estas cosas: nos preguntamos cómo eran nuestras vidas al momento de aquellos sucesos, casi todos ocurridos durante los años ochenta, que las definieron o las desviaron sin que pudiéramos siquiera darnos cuenta de lo que nos estaba sucediendo. Siempre he creído que así, comprobando que no estamos solos, neutralizamos las consecuencias de haber crecido durante esa década, o paliamos la sensación de vulnerabilidad que siempre nos ha acompañado. $Y$ esas conversaciones suelen comenzar con Lara Bonilla, ministro de Justicia. [...] "Estaba en mi cuarto, haciendo una tarea de química", dije. "¿Usted?”.

"Yo estaba enferma”, dijo Maya. "Apendicitis, imagínese, me acababan de operar" (p. 227).

La hacienda que Antonio y Maya encuentran al llegar es una deconstrucción -y destrucción - literal y física del mito de su infancia. En la finca, abandonada después de la muerte de Escobar en 1993, el tiempo ha hecho estragos: los protagonistas ven la propiedad devorada por la maleza, con estructuras de hierro y cemento cayéndose a pedazos, paredes ruinosas, vidrios sucios o rotos, la piscina llena de hojas secas, la colección legendaria de carros oxidándose en el garaje.

Aunque los restos de la hacienda representan una realidad estrechamente relacionada con un momento histórico determinado, para Maya y Antonio es un mundo atemporal, un viaje simbólico a la semilla de su trauma con el fin de superarlo. Al respecto, Alberto Fonseca (2015) observa:

Las ruinas de la hacienda Nápoles permiten a los personajes conectar el pasado, el presente y el futuro de la sociedad colombiana a la vez que demuestran la negociación que existe entre los ciudadanos del país con su pasado histórico. La visita que realizan a un lugar que se erige como sitio de intersección de sus diferentes historias, será un elemento esencial para entender a esta nueva generación de colombianos que viven en una sociedad Post-Pablo Escobar y que miran con nostalgia una infancia afectada por el narcotráfico (p. 84).

El tiempo circular o detenido de la hacienda, o una particular confusión del pasado, presente y futuro, junto a las connotaciones simbólicas de destrucción y abandono provocan tal interpretación de las ruinas en tanto representación de la tensión entre olvido y recuerdo que experimentan los personajes (pp. 89-90). Opinamos que esta y otras tensiones de variada índole relacionadas con la época del narcotráfico se reflejan igualmente en la oscilación entre el mito narco y las pruebas visibles de su destrucción. 
Es interesante que lo único que en la finca — caída a pedazos — se mantiene en un estado relativamente bueno sea

[...] el portal blanco de dimensiones innecesarias — una tractomula habría podido pasar por allí -, y sobre el travesaño, en delicado equilibrio, estaba una avioneta pequeña, blanca y azul como el portal: era la Piper que Escobar usó durante sus primeros años y a la cual, solía decir, debía su riqueza. Pasar por debajo de esa avioneta, leer la matrícula inscrita en la parte inferior de las alas, fue como entrar en un mundo sin tiempo (Vásquez, 20II, pp. 232-233).

Parece significativo que lo que se resiste a la decadencia vertiginosa sea el símbolo más literal, más palpable de la fuente de la riqueza del propietario de la hacienda. La avioneta constituye un monumento particular del narcotráfico; el estado actual del lugar, convertido en antimonumento, es un recordatorio del fracaso del espejismo de la narcocultura.

Si hablamos de El ruido de las cosas al caer como una anti-narconovela o una narconovela subvertida, se debe en gran medida a esta imagen de la sinécdoque de la narcocultura que era la Hacienda Nápoles, destruida, abandonada, despojada de su encanto, convertida en un anti-monumento. Desde una perspectiva histórica, la novela de Juan Gabriel Vásquez sugiere cierto fracaso del narcotráfico y su cultura. Los mitos del dinero fácil del narco, del ascenso social, del narcoparaíso se van deconstruyendo conforme progresa la "terapia” de los protagonistas.

\section{Literatura como terapia}

El fracaso ético y estético de la narcocultura (¿sugerido?, ¿postulado?) se puede observar también en el manejo particular del siguiente ingrediente de la convención literaria narco, a saber, un enfrentamiento dinámico de paradigmas culturales que en la mayoría de narconovelas demuestra cómo la cultura tradicional y elitista sucumbe bajo el ímpetu de lo popular y de una narcocultura estridente y exagerada. La propuesta estética de Vásquez va en el sentido contrario.

El primer aspecto relevante es en este caso la dimensión metanarrativa de la novela. El relato, escrito por Antonio varios años después de los acontecimientos narrados, es un interesante maridaje de oralidad y escritura. Dice el narrador:

Poco a poco me fui dando cuenta, no sin algo de pasmo, de que la muerte de ese hipopótamo daba por terminado un episodio que en mi vida había comenzado tiempo atrás [...].

Y es así que se ha puesto en marcha este relato. Nadie sabe por qué es necesario recordar nada, qué beneficios nos trae o qué posibles castigos, ni de qué manera puede cambiar lo vivido cuando lo recordamos, pero recordar bien a Ricardo Laverde se ha convertido para mí en un asunto de urgencia. 
He leído en alguna parte que un hombre debe contar la historia de su vida a los cuarenta años, y ese plazo perentorio se me viene encima: en el momento en que escribo estas líneas, apenas unas cuantas semanas me separan de ese aniversario ominoso. La historia de su vida. No, yo no contaré mi vida, sino apenas unos cuantos días que ocurrieron hace mucho, y lo haré además con plena conciencia de que esta historia, como se advierte en los cuentos infantiles, ya ha sucedido antes y volverá a suceder. Que me haya tocado a mí contarla, es lo de menos (Vásquez, 20II, p. If).

El fragmento, de evidente carácter metanarrativo, manifiesta que el orden del relato será el de la memoria, de los recuerdos, propio de las narraciones orales. Además, Antonio inscribe su historia en la tradición popular de cuentos infantiles (y a la vez en la postmoderna de reescrituras e intertextualidad), anunciando igualmente, desde el principio, su carácter colectivo. Sin embargo, es él quien la escribe, y el acto de escribir supone una suerte de catarsis y punto final de la experiencia vivida. La escritura se configura en la novela como una actividad indudablemente terapéutica. En una de las visitas, el médico de Yammara le entrega un cuaderno y le aconseja llevar un diario, a modo de terapia íntima, en el cual apuntar sus dudas y preguntas. Le aclara que "Es importante distinguir las preguntas pertinentes de las que no lo son [...] y una forma de hacerlo es ponerlas por escrito" (p. 67). En aquel momento el protagonista logra apuntar solamente “”, nada más. Será necesario que conozca a Maya y que comparta con ella la reconstrucción y terapeutización de la época de su adolescencia para concebir definitivamente el relato.

Cabe subrayar que, salvo la Hacienda Nápoles en su papel simbólico y sinecdóquico, la narcocultura en sí misma no aparece en El ruido de las cosas al caer. Lo que sí resalta es una tensión tradicional entre la capital y la provincia, interpretada a veces como una de las circunstancias que hicieron posible el desarrollo del narcotráfico (Henao Uribe, 2018, p. 167). En la novela, dicha tensión se traduce en el enfrentamiento dinámico de paradigmas culturales, en el plano geográfico en este caso, de cuyo choque nace el relato de Antonio Yammara. Hemos dicho anteriormente que, para vivir su experiencia casi mística y llenar los vacíos de la historia, el narrador tiene que salir de Bogotá e ir a la tierra caliente. Si bien allí accede al archivo familiar que documenta la vida de Ricardo Laverde y Elaine Fritts, lo verdaderamente relevante lo conoce debido a la narración oral de Maya, quien hace el trabajo de historiadora: a partir de documentos sueltos y fragmentados, de sus propios recuerdos y testimonios de otros, teje una narración coherente. Ella narra, Antonio escribe. No obstante, resulta que la historia narrada y escuchada en la 
tierra caliente solo puede escribirse desde Bogotá. Yammara, "el narrador letrado y el hombre de leyes, es finalmente quien dispone de todos los elementos para organizar el relato. Esta no es una historia que se pueda contar, al menos literariamente, desde la provincia” (Henao Uribe, 2018, p. 166). Lo sugiere la propia Maya Fritts al observar que "El papel no dura nada en esta humedad..." (Vásquez, 2011, p. 110).

\section{Lo culto como subversión}

En El ruido de las cosas al caer el paradigma culto predomina sobre la cultura popular, mientras que la narcocultura queda reducida a un símbolo (aunque crucial para el argumento de la novela). La línea culta en que se inscribe queda subrayada por una densa red de alusiones y referencias literarias presentes en la obra que nos remiten al siguiente elemento de la convención y poética narco: la intertextualidad e intermedialidad. La inserción de otros textos literarios orienta la lectura de la novela de Vásquez hacia lo culto, alejándola tajantemente de todo producto de la narcocultura, lo que constituye otro factor que nos permite calificar El ruido de las cosas al caer como una antinarconovela o una narconovela subversiva del paradigma narco. La palabra “subversiva” parece justificada, ya que la novela desemboca en la poesía, convirtiendo un poema de Aurelio Arturo en una clave interpretativa del reencuentro - o reconciliación - del protagonista terapeutizado con su ciudad y su propia vida.

Para Aníbal González (2016), la presencia de la poesía invita a leer la novela en clave lírica, intimista, e incluso permite "el desciframiento de un mensaje soterrado dentro de una constelación de símbolos que se 'llaman' oscuramente los unos a los otros dentro del texto como en el forêt de symboles del célebre soneto de Baudelaire” (p. 474). En la novela aparecen varias referencias a la obra de José Asunción Silva, el mayor poeta modernista colombiano, y de Aurelio Arturo, continuador o prolongador del legado del primero. Según González, la novela está escrita

[...] desde una perspectiva ampliamente influida por el tono poético de Aurelio Arturo si se toma en cuenta, como observa la crítica del poeta de Nariño, que la narratividad en la poesía de Arturo se expresa como una especie de serena reconciliación con la historia, con los hechos a veces traumáticos del pasado (p. 475).

Previamente, en una entrevista, Vásquez confirmó la importancia de la poesía y de los poetas mencionados para la obra al mencionar la influencia de la poesía en la dimensión estética de la novela, el valor supremo de la eufonía (De Maeseneer, 2013,p. 211). 
No obstante, desde el punto de vista del choque de paradigmas culturales, lo más interesante en la novela es el papel que en la trama desempeña la Casa de Poesía Silva, institución cultural ubicada en la antigua casa del poeta en La Candelaria. Poco antes del atentado, Yammara lleva a Ricardo Laverde a la Casa Silva para que el hombre pueda escuchar un misterioso casete que ha traído y que contiene la grabación de la caja negra del avión estrellado en el que murió Elaine Fritts. Mientras Laverde escucha la cinta, Antonio hace lo propio con la poesía de Silva. Cuando está escuchando el "Nocturno III" se percata del llanto de Ricardo; sin saber qué hacer, cierra los ojos y se sumerge en la poesía. Tras volver a la realidad, descubre que Laverde ya no está. Al salir a buscarlo en la calle, Yammara continúa oyendo en su mente un verso del nocturno ("Y eran una sola sombra larga"), sin que se le despegara incluso cuando ocurre el atentado. Estamos ante una simultaneidad impresionante: la tragedia de Laverde es simultánea al deleite de Yammara con el poema; el ruido del avión que cae y, posteriormente, los disparos resuenan simultáneos al verso en la mente del protagonista. La violencia y la poesía se configuran como dos caras de la misma realidad.

Dada la idea de la eufonía expresada por el propio autor y las numerosas referencias a sonidos, debemos dar cuenta del papel protagónico del sonido y de la importancia del casete en tanto objeto simbólico en la novela de Juan Gabriel Vásquez. Indicamos que la intermedialidad es uno de los ingredientes de la narconovela; en El ruido de las cosas al caer dicho casete puede interpretarse como parte de la dimensión metaliteraria de la obra, evocando (y anunciando), además, la transmedialidad:

El casete es un evidente sucedáneo de la escritura, es otra forma de escritura, en la cual se conserva y reproduce la dimensión sonora y se reduce al mínimo la visual. [...]

El casete, propongo, es un símbolo de la propia novela en la cual se encuentra, específicamente de la poética implícita de la novela que nos propone Juan Gabriel Vásquez en esta obra: se trata de la novela vista como casete, como grabación o registro de algunos hechos, o más precisamente de los sonidos que acompañan a los hechos. Escribir es registrar sonidos, el "ruido" de las cosas; leer es atender a esos sonidos y con ellos reconstruir las cosas separadas y fragmentadas por la distancia, para devolverles, o quizá inventarles, su forma. Si la poesía, como nos dice la preceptiva, es una invitación a darles forma a las cosas, la presencia de la poesía en esta novela apunta a la tarea siempre retadora que afronta el novelista de buscar darle forma al más informe de los géneros literarios. Más aún, la pequeñez y el carácter reproducible del casete, el precursor no tan remoto de nuestros medios digitales, sugiere que para Juan Gabriel Vásquez la "cosidad" de la novela depende menos de su soporte material - ya sea libro, casete o audiolibro - que del patrón de sonidos, el diseño repetible que puede dársele a las "palabras volanderas" para que, en su caída libre, ellas nos puedan comunicar su urgente mensaje (González, 2016, p. 47\%). 
Desde luego, la red de relaciones intertextuales e intermediales que enriquecen la interpretación de la novela y la arraigan en la tradición literaria es mucho más extensa y mucho más densa. La configuración de los personajes de El ruido de las cosas al caer remite a la literatura infantil: a los cuentos de hadas, a Peter Pan, a El Principito. En su trabajo exhaustivo, Priscilla Gac-Artigas (2015) enumera estas y otras alusiones literarias, entre ellas, ecos de Cien años de soledad, de Hamlet y de Ilíada. Según la investigadora,

El ruido de las cosas al caer a través de alusiones literarias que traspasan los géneros y las épocas, nos hace reflexionar no solamente sobre la omnipresencia de la violencia individual y colectiva en la historia de la humanidad al mostrar una historia que "ya ha sucedido antes y volverá a suceder" (I5), sino también sobre nuestra parte de responsabilidad en el marco de la violencia que nos haya tocado vivir, desafiándonos a través del personaje de Maya: “Como si la inocencia existiera en este país nuestro" (247) (p. 177).

La intermedialidad, a su vez, está presente en la novela de forma doble, tanto en el nivel del relato como en el de la historia narrada. La noticia mediática, por su parte, es el detonador del relato. Yammara cita casi literalmente la noticia de "una revista importante" (Vásquez, 2011, p. 13). Laverde habla de los animales de la Hacienda Nápoles tras ver la imagen de las ruinas en la televisión. La tradición "aérea" de la familia Laverde se conoce debido a un artículo de la revista Cromos en el que se relata el testimonio de un sobreviviente de la tragedia de Santa Ana ocurrida en 1938; es el padre de Ricardo. El artículo se cita in extenso. Dado que los hechos mencionados en realidad aparecieron en los medios de comunicación de la época, su referencia dota a la novela de realismo y contribuye a borrar deliberadamente la frontera que separa la ficción del periodismo.

En la historia del trauma de los protagonistas, las relaciones mediáticas desempeñan un rol crucial al aportar noticias, comentarios y sobre todo imágenes, que van provocando en los bogotanos un "temor mediado" (Henao Uribe, 2018, p. 165). Las informaciones de los actos de violencia les llegan a los protagonistas a través de los medios masivos. Su experiencia traumática consiste, de hecho, en ser espectadores de una violencia que termina por crear una historia compartida entre ellos. El miedo, provocado por la realidad relatada en los medios,

[...] actúa como un factor afectivo que construye ciudadanía, impone nuevas formas de usar el espacio de la ciudad, de relacionarse con los otros y consigo mismo y que tiene el potencial de limitar o promover efectivamente la agencia política de sus habitantes (Henao Uribe, 2018, p. 164).

De esta forma, lo mediático se configura como la fuente misma de la realidad privada. 
El ruido de las cosas al caer de Juan Gabriel Vásquez maneja todos los ingredientes propios de la convención literaria narco: configura el mundo representado a partir de bipolaridades y dicotomías en varios planos, lo somete en cierta medida a una distorsión antirrealista, recurre a la primera persona gramatical con trazas de oralidad, enfrenta lo culto con la narcocultura y ostenta su carácter intertextual. No obstante, la perspectiva histórica adoptada impone ciertas transformaciones dentro del paradigma. Dichas transformaciones pueden incluso subvertir el paradigma narco, convirtiendo la obra en una narconovela "antinarconovelesca".

Como en el centro del argumento se sitúan las consecuencias psicológicas del narcotráfico "a largo plazo" y la influencia del narcoterrorismo en la realidad privada de los protagonistas, las manifestaciones de la narcocultura brillan por su ausencia, salvo las ruinas de la Hacienda Nápoles en su papel simbólico y desmitificador.

Varias de las narconovelas colombianas plantean el problema del enfrentamiento de la cultura letrada y la narcocultura; los ejemplos más emblemáticos son $\mathrm{La}$ Virgen de los sicarios (1994) de Fernando Vallejo y Cartas cruzadas (1995) de Darío Jaramillo Agudelo. A diferencia de estas novelas, la de Vásquez indica claramente la preponderancia de la alta cultura tanto en la historia narrada como en el propio relato profundamente arraigado en la tradición culta de la literatura colombiana y universal. Vásquez no enfatiza la fuerza "devoradora" de la narcocultura; por el contrario, pone al descubierto el carácter ilusorio y destructor de su axiología, afirmando el valor terapéutico y salvador de la alta cultura, en particular el de la poesía.

En este sentido, El ruido de las cosas al caer puede leerse como una obra parteaguas de las narconarrativas de las décadas de 1990 y 2000. Enfocar la historia desde una perspectiva de la generación de los hijos, a 20 años de la muerte de Pablo Escobar, da cuenta de los costos psicológicos y sociales de la época del narcoterrorismo, diagnostica el estrés postraumático generacional y propone una terapia en el plano colectivo. Sin negar la culpa y las complicidades, se concentra en las víctimas. Apuesta por la cultura letrada como antídoto contra los espejismos de la narcocultura.

Publicada en 2011 y escrita por un autor nacido en los años setenta, la obra y las transformaciones de los paradigmas estético y ético que manifiesta la narconovela permiten formular algunas suposiciones e hipótesis acerca del futuro del paradigma narco en la novela colombiana: un inevitable maridaje de la narconovela con la modalidad de la novela histórica, evolución del patrón que representa la emergencia y 
cumbre de la narcocultura hacia la antinarconovela que plantea el tema de su fracaso estético y axiológico, la relevancia creciente de la intermedialidad y la representación de la realidad como una creación mediática.

\section{Referencias bibliográficas}

Albornoz Vásquez, M. V. (2017). El miedo y la memoria en El ruido de las cosas al caer de Juan Gabriel Vásquez. Diablotexto Digital 2, pp. 52-67.

De Maeseneer, R. (2013). Un fósforo en la oscuridad. Conversación con Juan Gabriel Vásquez. Confluencia 28 (2), pp. 209-216.

Dueñas, G. P. (2014). De cómo leer el narcotráfico y otras advertencias. Apuntes CECYP 24 (2), pp. 177-185. Fernández Luna, P. (2013). El ruido de las cosas al caer: la conciencia histórica como respuesta a la estética de la narconovela en Colombia. La palabra 22, pp. 29-39.

Fonseca, A. (2015). Revisitando la Hacienda Nápoles: las ruinas del narcotráfico en El ruido de las cosas al caer (2011) de Juan Gabriel Vásquez. En C. López Badano (Comp.). Periferias de la narcocracia. Ensayos sobre narrativas contemporáneas (pp. 79-91). Buenos Aires: Ed. Corregidor.

Gac-Artigas, P. (2015). El ruido de las cosas al caer o la reconstrucción de una era. Revista de la Academia Norteamericana de la Lengua Española IV (7), pp. 165-180.

González, A. (2016). Entrando en materia: novela, poesía y cultura material en El ruido de las cosas al caer. Cuadernos de literatura 20 (40), pp. 465-477.

Henao Uribe, L. (2018). Cartografías de violencia: centros, provincias y circulación transnacional en $E l$ ruido de las cosas al caer, de Juan Gabriel Vásquez. Estudios de Literatura Colombiana 42, pp. 157-173. DOI: https://doi.org/10.17533/udea.elc.n42a09

Herrero-Olaizola, A. (2007). “Se vende Colombia, un país de delirio”: El mercado literario global y la narrativa colombiana reciente. Symposium: A Quarterly Journal in Modern Literatures 61 (1), pp. 43-56.

Jácome, M. (2016). ¿Narco-novela o novela del narcotráfico? Apuntes sobre el caso colombiano. En B. Adriaensen, M. Kunz (Eds.). Narcoficciones en México y Colombia (pp. 27-52). Frankfurt: Iberoamericana/Vervuert.

Molina Lora, L. E. (2011). Narrativa de drogas: una investigación transatlántica en la producción cultural de España, México y Colombia [tesis de doctorado sin publicar]. Ottawa: University of Ottawa. Recuperado de https://ruor.uottawa.ca/bitstream/10393/20003/1/Molina Lora \%20Luis Eduardo 2011 thesis.pdf [15.02.2021]

Olvera, R. G. (2013). Sólo las cruces quedaron: Literatura y narcotráfico. México: Ficticia Editorial. Vásquez, J. G. (2011). El ruido de las cosas al caer. Bogotá: Alfaguara. 